\title{
Workforce planning and flexible working in the NHS of the future
}

\author{
AL Brown \\ Chair of RCPE Less Than Full Time Working Group; Consultant Nephrologist, Freeman Hospital, Newcastle upon Tyne Hospitals NHS \\ Foundation Trust, Newcastle upon Tyne, UK
}

KEYWORDS Feminisation, workforce, flexibility, less than full-time, portfolio career

Correspondence to A Brown

DECLARATION OF INTERESTS No conflict of interests declared.

e-mail alison.brown5@nuth.nhs.uk

There is an increasingly urgent need to review working patterns and future workforce planning now that women make up $42 \%$ of all doctors - $28 \%$ of hospital consultants and $47 \%$ of GPs.' Within a few years, predicted to be between 2017 and 2022, the majority of the medical workforce will be female. ${ }^{2}$ Already in 2010 there were $46 \%$ more female foundation year one (FI) doctors than male. ${ }^{2}$ The age distribution of the current workforce has also altered significantly, with the recent rise in output from medical schools, with many of today's workforce yet to start their families.

Thus, in future, even traditionally male-dominated intensive hospital specialities with unpredictable out-ofhours work will have to adapt to ensure they can attract and retain enough of the future predominantly female workforce to maintain their out-of-hours cover at a safe and sustainable level in European Working Time Directive (EWTD) compliant rotas.

Of course, the need for flexible and variable ways of working at different career stages is equally important for men and women, with family commitments or childless - we are all striving for a manageable work-life balance which enables us to keep ourselves fit and care for children or elderly relatives. Many of us have already experienced great changes in our working patterns, from the old days of working one night in every two on call to current EWTD limited rotas. We are all acutely aware of the need for improved working patterns that are more family friendly - essential if the National Health Service (NHS) is to retain doctors with family commitments, and ensure that future generations are able to contribute to the NHS, often at variable levels at different stages, throughout their whole career. In order to make certain that the UK medical school intake, currently about $60 \%$ women, translates into a motivated workforce who have a free choice of flexible, variable and individualised career pathways, we need to ensure that such career options are more easily and widely available than at present - while operating within the increasing financial constraints that are already in place. We have seen these workforce changes coming for some time and several reports have addressed possible solutions:
The 2008 Medical Women's Federation Making part time work report ${ }^{3}$ recommended that 'employers and Royal Colleges should work together to ensure that rota design can routinely incorporate part-time workers, and medical directors should support and promote innovative job design'.

Baroness Deech in 2009 recommended that the medical workforce planning apparatus took account of the increasing number of women in the medical profession; her report stated that 'NHS Medical Education England and the Centre for Workforce Intelligence should ensure that workforce models for the future clearly delineate the effect of a rising number of women in the workforce so that appropriate advice for the workforce planning apparatus can be given.'

The 2009 Women in medicine report to the Royal College of Physicians of London considered how this could be achieved, saying that 'changes in job design, particularly the move to more scheduled shift work, may lead to more predictable working patterns (albeit not necessarily confined to 'office hours') in some acute specialties. Average contracted working hours for fulltime NHS doctors are likely to decrease further with full implementation of EWTD. These changes may have implications for flexible working opportunities and, possibly, for the distinction between "full-time" and "less than full-time" working'. ${ }^{5}$

The Temple report in 2010 addressed workforce issues and also the challenge of maintaining safe and effective patient care and training within the constraints of EWTD rotas, reporting that 'good rota design and management enables compliance with the EWTD and an improved work-life balance' and highlighting the need for consultants to 'work more flexibly to deliver high quality training and service'. ${ }^{6}$

It seems reasonable to assume that the future workforce will have a longer working life, working initially to repay larger student debts, and subsequently to contribute more to pensions until a later retirement age. All the more important, therefore, that we take note of the messages of the Equal Opportunities in Medicine 
Symposium at the Royal College of Physicians of Edinburgh, which provoked considerable media interest, and recognise that a work-life balance is necessary for all doctors if they are to survive in the NHS of the future. Equality of opportunity for career development for those working less than full-time, who have exactly the same requirements in training, competency and preparation for revalidation as their full-time colleagues, may be even more of a challenge in future with more flexible and varied career paths. Speakers at the symposium highlighted the benefit of a mentor to advise on career progression, and the importance of engaging with areas of interest as soon as possible, while recognising that the amount of contribution may fluctuate over time depending on other responsibilities.

Scottish Government Deputy First Minister and Cabinet Secretary for Health, Wellbeing and Cities Strategy Nicola Sturgeon spoke eloquently to the symposium about the future challenges facing the NHS and emphasised the strong support from Scottish Government for equal opportunities for those doctors choosing to work less than full-time.

Evolving future working patterns, which adhere to EWTD limits and provide more senior out-of-hours cover and training, will bring many challenges but should also make it easier for variable individualised working patterns that are predictable, though not necessarily $9 \mathrm{am}$ to $5 \mathrm{pm}$, to become widespread and accepted. This may require redesign of service delivery, while future financial constraints are bound to restrict further workforce growth and impact on working patterns (and terms and conditions) for seniors and juniors alike, but units that respond with flexible working patterns will best be able to attract and retain future doctors.
Ultimately all of us, whatever our circumstances, are working to provide excellent and safe care for our patients at all times, while allowing a sustainable worklife balance throughout a working career where working hours can flex up and down at different stages of a 'portfolio' career.

It is the College's hope that this symposium will refocus attention on these issues, since despite widespread recognition that the future workforce will have different requirements, much remains to be done. We urge NHS employers, workforce units and trainee and consultant representatives to start working now to achieve improved rota flexibility and more individualised working patterns.

\section{REFERENCES}

I GMC-uk.org [Internet]. London: The General Medical Council; [updated 20II October 3; cited 20II Oct 26]. List of Registered Medical Practitioners - Registration statistics. Available at: http://www. gmc-uk.org/index.asp

2. General Medical Council. State of medical education and practice in the UK 201 I [Internet]. London: General Medical Council; 20II [cited $201 \mathrm{O}$ Oct 26]. Available from: http://www.gmc-uk.org/State_of_ medicine_Final_web.pdf_44213427.pdf

3. Medical Women's Federation. Making part time work [Internet]. London: Medical Women's Federation 2008; 2008 [cited 20l I Oct 26]. Available from: http://www.medicalwomensfederation.org.uk/ files/Part-time\%20full\%20report\%20final.pdf

4. National Working Group on Women in Medicine. Women doctors: making a difference [Internet]. London: Department of Health; 2009 [cited 201I Oct 26]. Available from: http://www.renal.org/ pages/media/Flexible\%20trainees/baroness\%20deech\%20 report\%20for\%20CMO\%20oct\%202009.pdf

5. Elston MA. Women and medicine: the future [Internet]. London: Royal College of Physicians; 2009 [cited 201I Oct 26]. Available from: http://bookshop.rcplondon.ac.uk/contents/bd2d994a-7d38465f-904a-2la70cdc7d9c.pdf

6. Temple J. Time for training: A review of the impact of the European Working Time Directive on the quality of training [Internet]. London: Medical Education England; 2010 [cited 20II Oct 24]. Available from: http://www.mee.nhs.uk/PDF/I4274\%20Bookmark\%20Web\%20 Version.pdf 